\title{
A FORMAÇÃO DE ESPAÇOS REGIONAIS DE EDUCAÇÃO SUPERIOR: UM OLHAR MERIDIONAL - PARA O MERCOSUL
}

\author{
Mário Luiz Neves de Azevedo
}

\begin{abstract}
*Professor no Programa de Pós-Graduação em Educação da UEM, doutor em educação pela USP, bolsistaprodutividade da Fundação Araucária.
Resumo: Este texto analisa o fenômeno da formação de espaços regionais de educação superior em um contexto de internacionalização.

Palavras-chave: Internacionalização. Mercosul. Processo de Bolonha.

\section{THE CREATION OF REGIONAL AREAS OF HIGHER EDUCATION: A LOOK SOUTH - FOR MERCOSUL}

\begin{abstract}
This article analyzes the creation of regional areas of higher education in a context of internationalization.
\end{abstract}

Key word: Internationalization. Mercosul. Bologna Process.

A educação superior, sendo um setor estratégico para o desenvolvimento de um país e um fator de integração entre países e nações, está inserida efetivamente no processo de integração regional.

Preservadas as proporções, o Processo de Bolonha na Europa e a Comissão Regional Coordenadora de Educação Superior do Mercosul têm sido fontes indutoras de reformas dos sistemas nacionais de educação superior com vistas à comparabibilidade, reconhecimento de créditos e mobilidade acadêmica entre os distintos sistemas nacionais de educação superior. No velho continente, a integração acadêmica, como conseqüência de um longo e intensivo processo de integração econômica, social e política, cujos marcos fundacionais foram a Comunidade Européia do Carvão e do Aço (CECA), de 1951, e o Tratado de Roma, de 1957, está efetivando-se, definitivamente, com o Processo de Bolonha, que tem por objetivo, desde o seu lançamento em 1999, a construção de um Espaço Europeu de Educação Superior (EEES) até o ano 2010. 
No Mercosul, apesar de inúmeros documentos assinados (tratados, convenções e resoluções), pouco tem se avançado para a integração dos sistemas nacionais/federais de educação superior com vistas a um espaço compartilhado de formação acadêmica e de pesquisa. A mais recente iniciativa refere-se ao Mecanismo Experimental de Credenciamento (MEXA) a ser aplicado aos Cursos de Graduação em Agronomia, Engenharia, Medicina, Odontologia, Veterinária e Arquitetura.

Desafio complementar para os países do Mercosul (Argentina, Brasil, Paraguai e Uruguai) é o de integrar seus próprios sistemas de educação superior e, concomitantemente, criar mecanismos de reconhecimento e mobilidade com sistemas extra-Mercosul como é o caso do futuro EEES que se encaminha para sua conclusão com o Processo de Bolonha. Dessa forma, apresentam-se a seguir uma discussão a respeito do fenômeno de internacionalização e, ao mesmo tempo, de regionalização da educação superior; tomando por referência o papel da avaliação e acreditação nesse fenômeno.

\section{Internacionalização e Integração Regional: Desafios e Implicações}

Essa que pode ser considerada uma política pública regional (de um metaEstado?) envolve muitas complexidades. As Instituições de Educação Superior (IES), ao aceitarem o convite de integração regional e de internacionalização, tacitamente, contraem mais obrigações do que propriamente o compromisso de integração internacional/regional. A internacionalização não é um fenômeno metafísico de transposição de fronteiras, mas, sim, um complexo processo de integração a um campo acadêmico mundializado em que os diversos atores sociais travam relações com vistas a intercambiar, a cooperar e a compartilhar solidariamente (ou, opostamente, a competir) no âmbito de suas ações sociais e espaços de influências no que se relaciona ao conhecimento, à ciência, à técnica às artes e a cultura.

As IES, em processo de internacionalização e regionalização, aceitam, ao mesmo tempo, outras pertinentes obrigações com a sociedade. As universidades que pretendem alcançar a internacionalização devem, simultaneamente, elaborar reflexões e ações a respeito da Integração Regional, do Desenvolvimento Sustentável e do Conhecimento Local. Ou seja, aquilo que seria uma tarefa eminentemente acadêmica, a internacionalização, torna-se um conjunto de quatro ações (tarefas) combinadas: 

a) internacionalização;
b) integração regional;
c) desenvolvimento sustentável;
d) respeito ao conhecimento local.

Além disso, a Alma Mater (Academia) não pode dispensar, em cada uma dessas ações/projetos, preocupações tais como: Pertinência Social, Qualidade Acadêmica, Avaliação/Accountability e Igualdade/Inclusão Social.

A proposta de se alcançar a internacionalização não é uma tarefa que se cumpre com esforços aleatórios e abstratos, mas é um movimento devidamente planejado em que atuam quatro vetores concomitantemente. A comunidade acadêmica, ao mesmo tempo em que necessita do diálogo internacionalizado, em sentido mundial, não pode desprezar o processo de regionalização, a exemplo do movimento de integração entre os países que compõem o Mercosul, tampouco as IES e suas comunidades acadêmicas correspondentes podem perder, cultural, geograficamente e historicamente, o sentido local de suas existências. Além disso, os atores sociais envolvidos na internacionalização da educação superior devem incorporar, teórica e praticamente, o conceito e ações de sustentabilidade.

Seria desnecessário dizer, porém, ressalte-se que a universidade deve adotar o procedimento de feedback à sociedade, retroalimentando-se em um processo em que o saber local, a integração regional e a internacionalização estejam assentadas, como uma praxe, sobre os princípios do desenvolvimento sustentável. A figura abaixo pode auxiliar no entendimento desse processo.

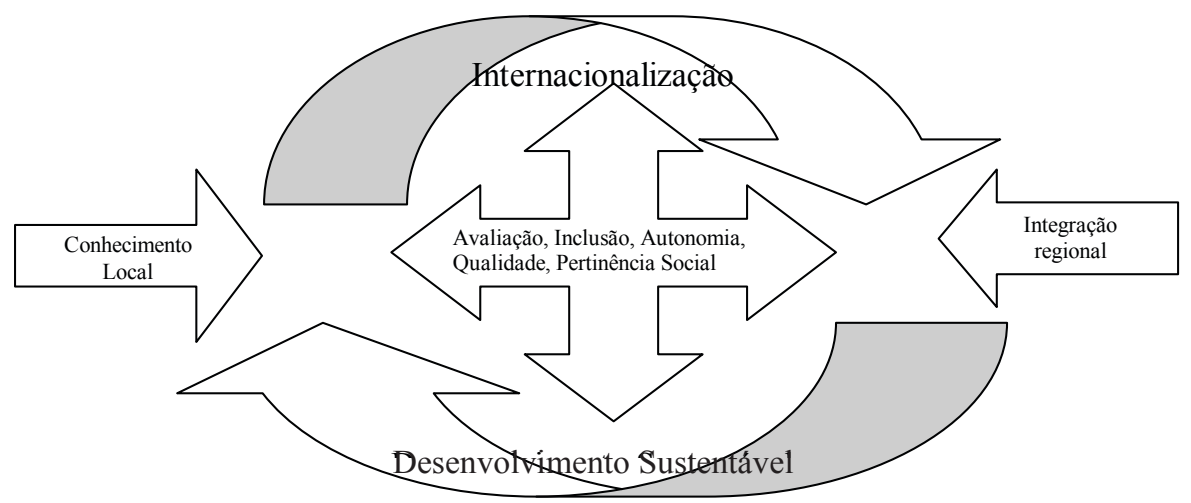


Incorporando-se a idéia de desenvolvimento sustentável e o respeito ao conhecimento local e reconhecendo o estado da arte e o histórico de políticas de integração na região, a internacionalização/regionalização aproxima-se do sucesso. Não se pode desprezar a história dos países envolvidos no processo de integração, pois a partir da formação dos Estados Nacionais, a história registra diversos movimentos de fustigação (guerras?) ou de alianças entre países vizinhos. Vários eventos na América Latina demonstram um efeito "sanfona" (acordeão), com aproximações e distanciamentos, desde os primeiros movimentos nacionais de libertação e de independência havidos nos países da região.

Com vistas a uma reflexão pró-positiva, dispensem-se menções às guerras e aos entreveros entre as nações latino-americanas e cite-se os movimentos que visa(ra)m a integração. Podem ser lembradas iniciativas como a ALALC (Associação Latino-Americana de Livre Comércio), ALADI (Associação Latino-Americana de Integração), chegando, atualmente, a CAN (Comunidade Andina de Nações), o Mercosul, CARICOM e a CASA (Comunidade Sul Americana de Nações),

Enfim, é necessário que as IES regionais, no concerto global das nações, não interpretem que devam aceitar um papel subalterno na produção científica e tecnológica. Atentar para as questões locais não significa descartar o domínio do conhecimento mais sofisticado e universalizado. Não é desconhecido o caminho de se combinar a produção de conhecimento baseado nos problemas locais em diálogo com a ciência global. A conhecida frase de Tolstoi o demonstra: "se queres ser universal, fala da tua aldeia"'.

Soluções para muitos dos problemas da humanidade, bem como, de um possível modelo de desenvolvimento sustentável, inclusive no que refere às energias renováveis podem ser encontrados em paralelos ao Sul (em blocos regionais ou não) e dependem, em grande medida, da valorização do saber local e da institucionalização da internacionalização solidária.

\section{Considerações Finais}

Pode parecer uma tarefa mitológica, daquelas em que personagens e entidades propõem-se a desígnios sobrenaturais, entretanto a internacionalização, a regionalização, o respeito ao conhecimento local e a aceitação dos princípios

\footnotetext{
1 Fernando Pessoa (heterônimo Alberto Caieiro) declama sobre o local e o global.

" Da minha aldeia vejo quanto da terra se pode ver no Universo...

Por isso a minha aldeia é tão grande como outra terra qualquer

Porque eu sou do tamanho do que vejo

E não, do tamanho da minha altura [...]"
} 
do desenvolvimento sustentável dependem que as instituições universitárias conquistem definitivamente a autonomia, tenham qualidade, sejam inclusivas e pertinentes socialmente e permitam-se a avaliação. Essas características completam socialmente quaisquer que sejam as missões acadêmicas assumidas pelas IES.

Nesse sentido, destaque-se o papel que a avaliação e a acreditação desempenham no processo de integração e que existe uma tendência de formação de agências avaliadoras/acreditadoras abrangendo, no mínimo, o espaço regional integrado. Essas agências teriam o papel de avaliar, acreditar e de chancelar ("labelizar") as IES em um ambiente internacional. Entretanto, para que se respeite o princípio da autonomia universitária, seria positivo que a avaliação fosse voluntária, formativa e participativa, com o sentido do auto-conhecimento e da solidariedade, descartando-se o imediatismo dos rankings ${ }^{2}$.

2 Segundo o Dicionário Houaiss (Rio de Janeiro: Objetiva, 2004), etimologicamente, ranking tem origem na língua inglesa (1862) e significa "estar em uma posição alta, estar próximo ao chefe" (Qual chefe? Eis a questão) 